06

\title{
Методы атомно-силовой микроскопии для исследования суперпротонных кристаллов
}

\author{
(C) Р.В. Гайнутдинов, А.Л. Толстихина, Е.В. Селезнева, И.П. Макарова \\ Институт кристаллографии им. А.В. Шубникова ФНИЦ „Кристаллография и фотоника“ РАН, \\ 119333 Москва, Россия \\ I e-mail: alla@ns.crys.ras.ru
}

Поступило в Редакцию 3 апреля 2020 г.

В окончательной редакции 3 апреля 2020 г.

Принято к публикации 3 апреля 2020 г.

Проведены комплексные исследования новых кристаллов-суперпротоников — кислых солей сульфата калия-аммония $\left(\mathrm{K}_{1-x}\left(\mathrm{NH}_{4}\right)_{x}\right)_{3} \mathrm{H}\left(\mathrm{SO}_{4}\right)_{2}, x \geq 0.57$. Методами атомно-силовой микроскопии получены данные о морфологии поверхности, доменной структуре и проводимости образцов. Впервые стабильность и деградация поверхности суперпротонных кристаллов изучена на наноуровне. На основе данных микроскопии пьезоэлектрического отклика установлено, что при понижении температуры от 296 до $282 \mathrm{~K}$ кристалл $\left(\mathrm{K}_{0.43}\left(\mathrm{NH}_{4}\right)_{0.57}\right)_{3} \mathrm{H}\left(\mathrm{SO}_{4}\right)_{2}$ переходит из пара- в сегнетоэлектрическую фазу.

Ключевые слова: кристаллы-суперпротоники, пьезоэлектрический отклик, суперпротонный кристалл.

DOI: 10.21883/JTF.2020.11.49972.116-20

\section{Введение}

Кристаллы-суперпротоники состава $M_{m} \mathrm{H}_{n}\left(A \mathrm{O}_{4}\right)_{(m+n) / 2}$ $\times y \mathrm{H}_{2} \mathrm{O}\left(M=\mathrm{K}, \mathrm{Rb}, \mathrm{Cs}, \mathrm{NH}_{4}, A \mathrm{O}_{4}=\mathrm{SO}_{4}, \mathrm{SeO}_{4}, \mathrm{HPO}_{4}\right.$, $\left.\mathrm{HAsO}_{4}\right)$ рассматриваются как перспективные материалы для создания различных электрохимических устройств. Одна из важнейших характеристик этих кристаллов высокая протонная проводимость, которая достигает $10^{-3}-10^{-1} \Omega^{-1} \cdot \mathrm{cm}^{-1}$ в диапазоне рабочих температур $320-500 \mathrm{~K}$. Проводимость этих материалов связана с их структурными особенностями, а не с допирующими добавками, что обусловливает их уникальность в классе протонных проводников [1]. Все кристаллы этого семейства претерпевают структурные фазовые переходы, при которых повышение температуры или замещение атомов приводит к такой перестройке системы водородных связей, что формируются вакантные кристаллографически эквивалентные позиции для движения протонов и протонная проводимость становится аномально высокой $[2,3]$.

Структурный анализ считается основным методом исследования механизмов фазовых переходов на атомном уровне. Однако для однозначной интерпретации полученных данных и установления закономерных связей между структурой и свойствами кристаллических материалов необходима дополнительная информация. С этой целью привлекаются различные динамические методы исследования, например, наблюдение образца в поляризованном свете при постоянном нагревании, дифференциальная сканирующая калориметрия и импедансная спектроскопия.

Ценным источником информации оказывается атомно-силовая микроскопия (ACM). Хотя изначально этот метод был предназначен для характеризации на наноуровне поверхности материалов, в настоящее время с помощью усовершенствованных техник можно получить качественно новые данные о функциональных свойствах материала в объеме - фазовых переходах, структурных субповерхностных неоднородностях, дефектной структуре, составе сложных гетерогенных систем и др. [4,5]. В этом плане особый интерес представляют электрические модификации АСМ [6]. Так, одна из них - микроскопия пьезоэлектрического отклика (МПО) - позволяет наблюдать in situ сегнетоэлектрические/сегнетоэластические фазовые переходы в кристаллах и тонких пленках [7,8]. Другая контактная электрическая методика - проводящая АСМ $($ ПАСМ) - дает возможность определять локальные электрические характеристики и устанавливать взаимосвязь топографической и электрической информации с пространственным разрешением в диапазоне от 0.1 до $100 \mathrm{~nm}[5,6]$. В ПАСМ зонд действует как подвижный электрод, обнаруживающий локальные изменения электрического тока. На основе электростатической силовой микроскопии и ее разновидностей развиваются также методы бесконтактного картирования состава гетерогенной поверхности $[9,10]$ и локальной диэлектрической спектроскопии [11].

Несмотря на широкие возможности АСМ для решения различных задач физического материаловедения, литературных данных по ее применению для изучения кристаллов-суперпротоников практически нет. Вероятно, это связано с техническими сложностями проведения подобных экспериментов. И прежде всего с ограничением температурного диапазона измерений коммерческих приборов, например, от 243 до $393 \mathrm{~K}$ в воздушной среде (ячейка MP6LC, HT-МДТ Spectrum Instruments). У большинства же суперпротоников переходы в фазу с высокой проводимостью происходят при более высоких 
температурах $(320-500 \mathrm{~K})$, недостижимых для измерений. Другой проблемой остается интерпретация целого ряда свойств суперпротонных фаз, что во многом связано с плохой воспроизводимостью экспериментальных результатов при повышенных температурах.

В настоящей работе мы представляем результаты исследования изоструктурных кристаллов-суперпротоников - кислых солей сульфата калия-аммония $\left(\mathrm{K}, \mathrm{NH}_{4}\right)_{3} \mathrm{H}\left(\mathrm{SO}_{4}\right)_{2}$ с содержанием аммония от 57 до $80 \%$ методами электрической АСМ. Особое внимание уделено кристаллу состава $\left(\mathrm{K}_{0.43}\left(\mathrm{NH}_{4}\right)_{0.57}\right)_{3} \mathrm{H}\left(\mathrm{SO}_{4}\right)_{2}$, поскольку он проявляет суперпротонную проводимость уже при комнатной температуре и его атомная структура установлена с высокой точностью [12]. В этом достаточно редком случае температура предполагаемого структурного перехода отвечает возможностям прибора. Изменение энергии активации проводимости и аналогия с поведением изоструктурных соединений при понижении температуры заставляют заподозрить при $T<293 \mathrm{~K}$ наличие фазовых переходов (пара-сегнетофаза) у этого кристалла [12] и близких по составу фаз [13]. В центре внимания оказались и вопросы, связанные с устойчивостью кристаллов к воздействию различных внешних факторов, поверхностные явления, которые могут приводить к временным изменениям электрофизических свойств, а также методические аспекты подготовки образцов и проведения измерений.

\section{1. Методика эксперимента}

Кристаллы $\left(\mathrm{K}_{2} \mathrm{NH}_{4}\right)_{3} \mathrm{H}\left(\mathrm{SO}_{4}\right)_{2}$ были выращены в Институте кристаллографии методом управляемого снижения растворимости из водных растворов $\mathrm{K}_{3} \mathrm{H}\left(\mathrm{SO}_{4}\right)_{2}$ и $\left(\mathrm{NH}_{4}\right)_{3} \mathrm{H}\left(\mathrm{SO}_{4}\right)_{2}$ при соотношении $\mathrm{K}^{+}: \mathrm{NH}_{4}^{+} \sim 3: 7 ; 2: 8$, $1: 9$. Кристаллизация проводилась в диапазоне температур $303-313 \mathrm{~K}$. Выращенные монокристаллы имеют характерный пластинчатый габитус (рис. $1, a$ ).

Кристаллы $\left(\mathrm{K}_{0.43}\left(\mathrm{NH}_{4}\right)_{0.57}\right)_{3} \mathrm{H}\left(\mathrm{SO}_{4}\right)_{2}$ с замещением калия на аммоний оптически изотропны и имеют тригональную симметрию, как и высокотемпературные суперпротонные фазы $\mathrm{K}_{3} \mathrm{H}\left(\mathrm{SO}_{4}\right)_{2}$ [14] и $\left(\mathrm{NH}_{4}\right)_{3} \mathrm{H}\left(\mathrm{SO}_{4}\right)_{2}$ [15]. При комнатной температуре кристаллы $\left(\mathrm{K}_{0.43}\left(\mathrm{NH}_{4}\right)_{0.57}\right)_{3} \mathrm{H}\left(\mathrm{SO}_{4}\right)_{2}$ имеют пространственную группу $R \overline{3}, Z=3, a=b=5.7768(3), c=22.0983(1) \AA$ [12]. Кристаллическая структура $\left(\mathrm{K}_{0.43}\left(\mathrm{NH}_{4}\right)_{0.57}\right)_{3} \mathrm{H}\left(\mathrm{SO}_{4}\right)_{2}$ показана на рис. $1, b$. Две другие исследуемые фазы $\left(\mathrm{K}_{0.33}\left(\mathrm{NH}_{4}\right)_{0.67}\right)_{3} \mathrm{H}\left(\mathrm{SO}_{4}\right)_{2}$ и $\left(\mathrm{K}_{0.20}\left(\mathrm{NH}_{4}\right)_{0.80}\right)_{3} \mathrm{H}\left(\mathrm{SO}_{4}\right)_{2}$ по предварительным структурным данным являются изоструктурными $\left(\mathrm{K}_{0.43}\left(\mathrm{NH}_{4}\right)_{0.57}\right)_{3} \mathrm{H}\left(\mathrm{SO}_{4}\right)_{2}$ и отличаются соотношением заселенности позиций $\mathrm{K} / \mathrm{N}$. На основе имеющихся данных можно предположить наличие низкотемпературных $(T<293 \mathrm{~K})$ сегнетоэлектрических/сегнетоэластических фазовых переходов у всех трех суперпротонных фаз и особенностей в их кинетике из-за небольшого различия химического состава [13].
Объектом изучения была поверхность (001) кристаллов, полученная свежим сколом на воздухе и отполированная по стандартной процедуре подготовки образцов для электрофизических измерений. АСМ-исследование образцов было проведено на микроскопе NTEGRA Prima (NT-MDT Spectrum Instruments, Зеленоград) в условиях чистой зоны контрольно-измерительного комплекса „TRACKPORE ROOM-05“ (класс чистоты 5 ИСО (100), точность поддержания температуры воздушной среды в чистой зоне в диапазоне $298 \pm 5 \mathrm{~K}$ составляла $0.05 \mathrm{~K}$, относительная влажность воздуха $30-50 \pm 1 \%$ ). Данные МПО, в основе которой лежит регистрация локального пьезоотклика материала при приложении переменного электрического поля к проводящему зонду, были получены в контактном режиме при напряжении амплитудой $4 \mathrm{~V}$ и частоты $350 \mathrm{kHz}$. Кремниевый кантилевер (HA_FM, балка B, Tipsnano, Эстония), покрытый Pt, имел следующие характеристики: резонансная частота $f=72 \mathrm{kHz}$, жесткость $k=3.5 \mathrm{~N} / \mathrm{m}$, радиус закругления острия $R<30 \mathrm{~nm}$. Токовые изображения получали методом ПАСМ в контактном режиме при подаче на нижний электрод постоянного напряжения $U_{d c}$. Локальные вольт-амперные характеристики (BAX) измерялись в диапазоне напряжений от -4 до $+4 \mathrm{~V}$. Рельеф поверхности образцов изучали в прерывисто-контактном режиме с использованием кантилеверов той же марки.

Температурные измерения локальных физических свойств кристаллов при понижении температуры проводили на микроскопе NTEGRA Prima (NT-MDT Spectrum Instruments, Зеленоград) со сканирующей измерительной головкой SMENA SFC102LNTF с контроллером $\mathrm{PB} 2,0$ для реализации прыжковой моды и ячейкой с контролем температуры MP6LC в пределах от 243 до $393 \mathrm{~K}$ в воздушной среде. Использовали кантилеверы марки NSG01/Pt того же производителя $(f=150 \mathrm{kHz}$, $k=5.1 \mathrm{~N} / \mathrm{m}, R=25 \mathrm{~nm}$ ). Переменное напряжение на острие зонда подавалось с амплитудой $8 \mathrm{~V}$ и частотой $160 \mathrm{kHz}$. Максимальная сила взаимодействия зондового датчика с поверхностью в процессе высокоскоростной силовой спектроскопии составляла $160 \mathrm{nN}$. Температура менялась трижды: с $296 \pm 0.1 \mathrm{~K}$ до $278 \pm 0.1 \mathrm{~K}$ и обратно.

\section{2. Результаты и их обсуждение}

Стандартным способом подготовки образцов водорастворимых кристаллов является раскол по плоскостям спайности. Методом АСМ были изучены особенности микро- и нанорельефа поверхности (001) кристаллов, формирующейся при свежем сколе на воздухе. На рис. 2, $a$ показано характерное изображение нанорельефа участка поверхности размером $5 \times 5 \mu \mathrm{m}$ кристалла $\left(\mathrm{K}_{0.43}\left(\mathrm{NH}_{4}\right)_{0.57}\right)_{3} \mathrm{H}\left(\mathrm{SO}_{4}\right)_{2}$. На атомно-гладкой поверхности образуются выступы различных латеральных размеров $40-250 \mathrm{~nm}$ одной и той же высоты $\sim 0.7-0.8 \mathrm{~nm}$ (рис. 2). На других участках ступенча- 

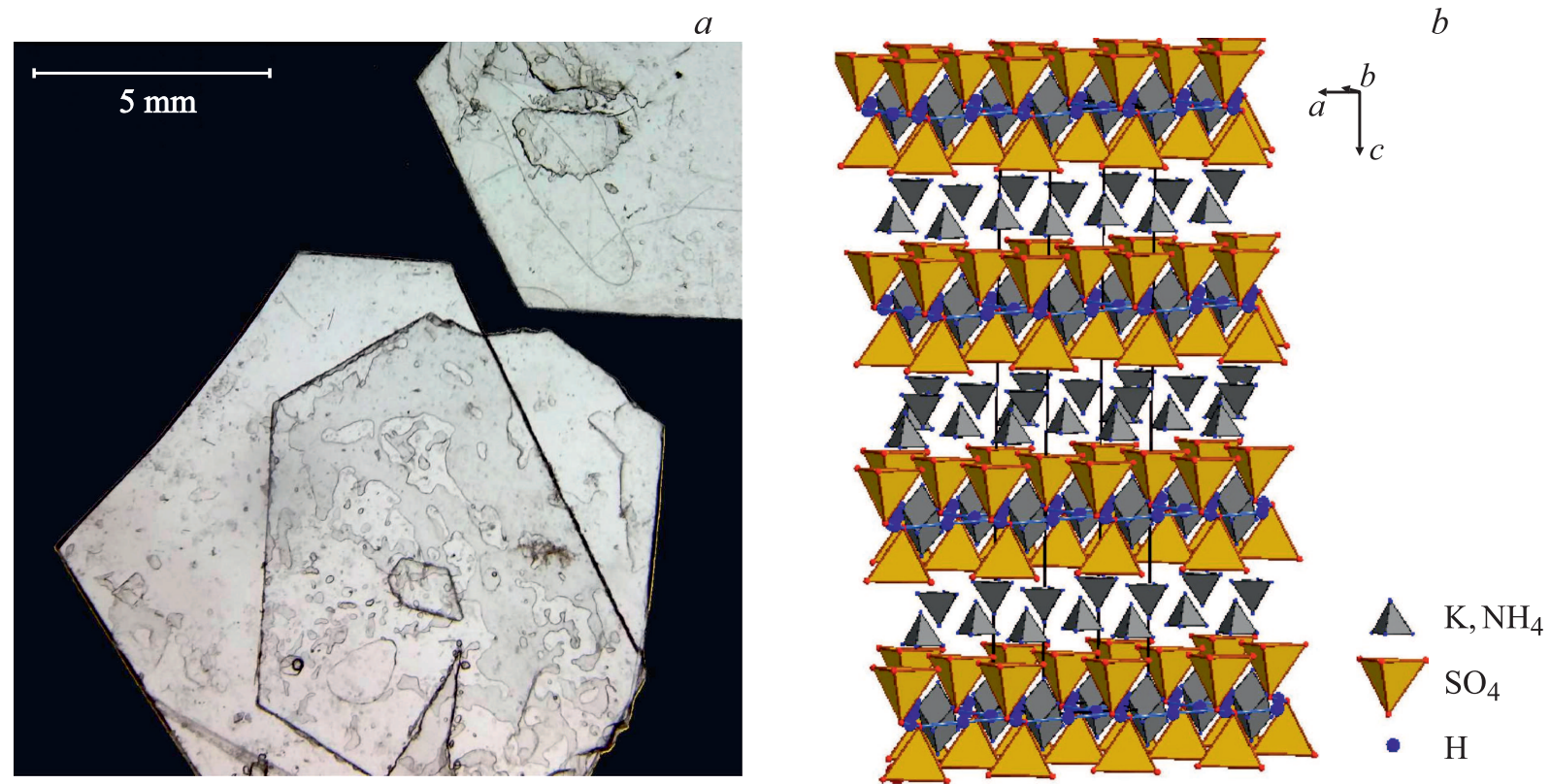

Рис. 1. Кристаллы $\left(\mathrm{K}_{0.43}\left(\mathrm{NH}_{4}\right)_{0.57}\right)_{3} \mathrm{H}\left(\mathrm{SO}_{4}\right)_{2}$. $a$ - габитус кристаллов, $b$ - атомная структура. Показаны тетраэдры $\mathrm{SO}_{4}$, соединенные водородными связями; отмечено расположение атомов К и групп $\mathrm{NH}_{4}$.
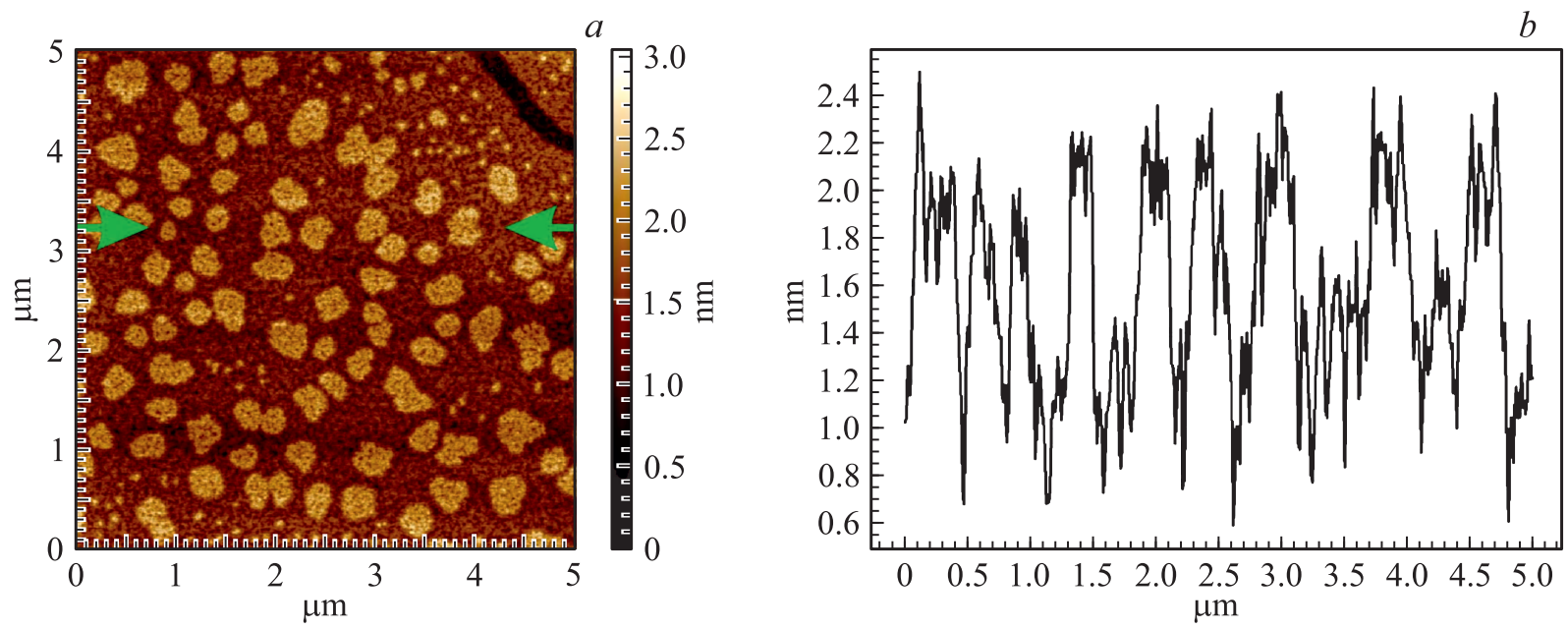

Рис. 2. $a$ - АСМ-изображение поверхности $(001)$ кристалла $\left(\mathrm{K}_{0.43}\left(\mathrm{NH}_{4}\right)_{0.57}\right)_{3} \mathrm{H}\left(\mathrm{SO}_{4}\right)_{2}$, полученной свежим сколом на воздухе при 40\% влажности, $b-$ профиль сечения.

той поверхности наблюдаются также ямки глубиной $\sim 0.7 \mathrm{~nm}$ с латеральными размерами 20-100 nm. Глубина/высота элементов нанорельефа поверхности исследуемого кристалла составляет примерно 1/3 с (кратна доле параметра элементарной ячейки). Изучение изображений фазового контраста показывает, что поверхность кристалла $\left(\mathrm{K}_{0.43}\left(\mathrm{NH}_{4}\right)_{0.57}\right)_{3} \mathrm{H}\left(\mathrm{SO}_{4}\right)_{2}$, полученная свежим сколом, однородна с точки зрения фазового состава. Образование ступенчатого нанорельефа в виде ямок и выступов с высотой/глубиной, кратной долям параметра элементарной ячейки, наблюдается также при расколе других водорастворимых кристаллов со спайностью, например, триглицинсульфата [16], причем относитель- ная стабильность и особенности нанорельефа атомногладкой поверхности позволяют косвенно оценивать дефектность кристалла в объеме.

Если обратиться к модели атомной структуры кристалла $\left(\mathrm{K}_{0.43}\left(\mathrm{NH}_{4}\right)_{0.57}\right)_{3} \mathrm{H}\left(\mathrm{SO}_{4}\right)_{2}$, можно видеть, что вдоль оси $c$ в элементарной ячейке располагаются три слоя тетраэдров $\mathrm{SO}_{4}$, соединенных водородными связями, среди которых и между которыми находятся позиции $\mathrm{K} / \mathrm{NH}_{4}$ (рис. $1, b$ ). То есть наблюдаемый поверхностный нанорельеф в виде ямок/выступов с глубиной/высотой, кратной 1/3 параметра элементарной ячейки, коррелирует с особенностями слоистой структуры кристалла $\left(\mathrm{K}_{0.43}\left(\mathrm{NH}_{4}\right)_{0.57}\right)_{3} \mathrm{H}\left(\mathrm{SO}_{4}\right)_{2}$. 

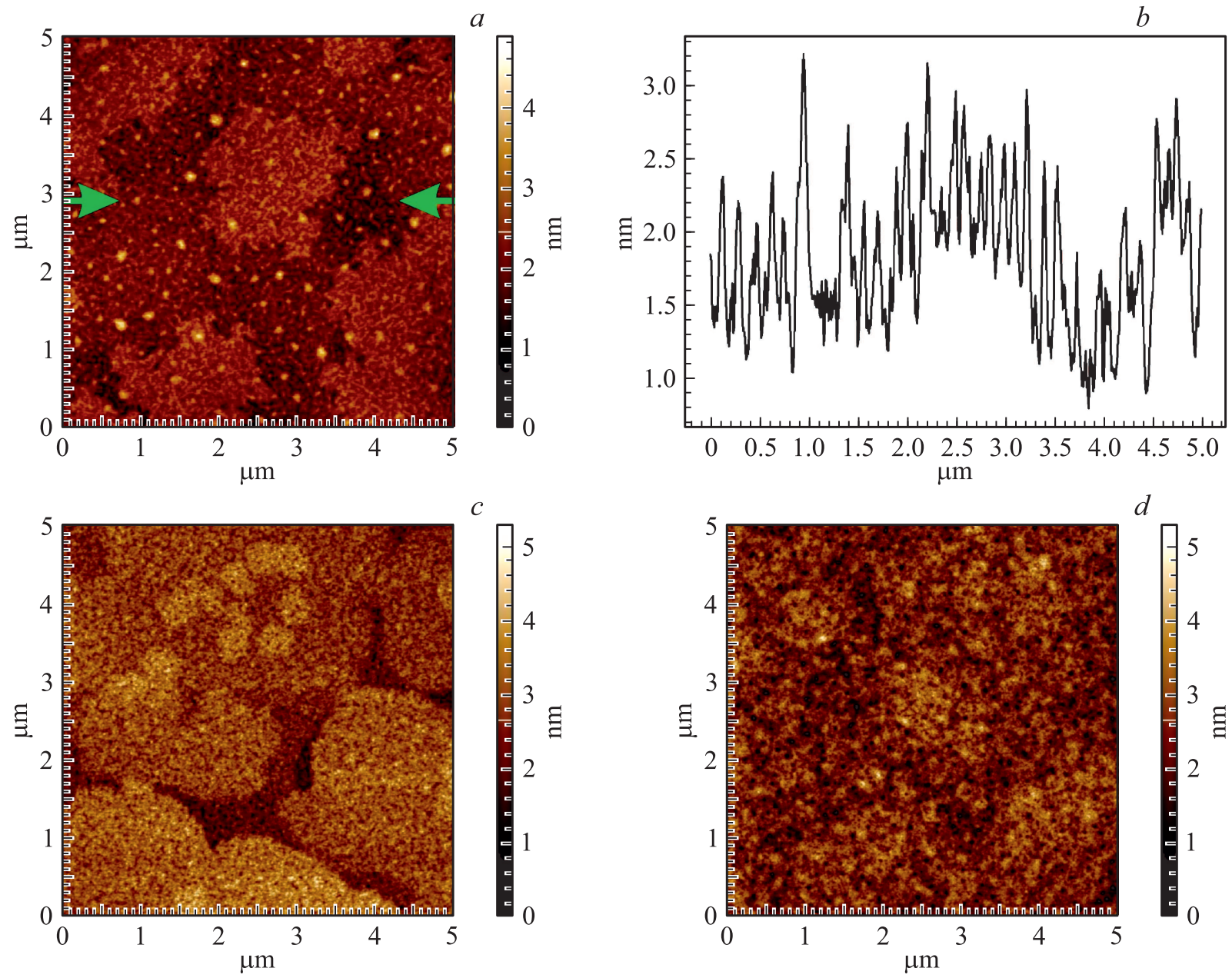

Рис. 3. АСМ-изображения поверхности свежего скола: $a-$ кристалла $\left(\mathrm{K}_{0.33}\left(\mathrm{NH}_{4}\right)_{0.67}\right)_{3} \mathrm{H}\left(\mathrm{SO}_{4}\right)_{2}$ при $40 \%$ влажности; $b-$ с соответствующим профилем сечения; $c-\left(\mathrm{K}_{0.20}\left(\mathrm{NH}_{4}\right)_{0.80}\right)_{3} \mathrm{H}\left(\mathrm{SO}_{4}\right)_{2}$ при $30 \%$ влажности; $d-$ при $40 \%$ влажности.

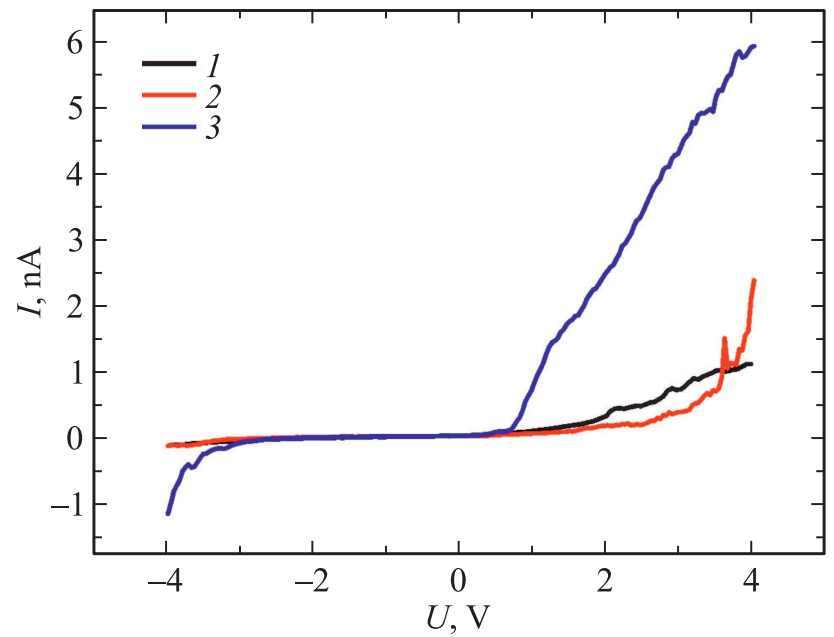

Рис. 4. Локальные ВАX для кристаллов $\left(\mathrm{K}_{2} \mathrm{NH}_{4}\right)_{3} \mathrm{H}\left(\mathrm{SO}_{4}\right)_{2}$ с содержанием аммония от 57 (1), 67 (2) и 80\% (3). Поверхность (001) получена свежим сколом.
В случае двух других фаз с более высоким содержания аммония (67 и 80\%) картина становится не столь очевидной. При свежем сколе на воздухе (40\% влажность) поверхность (001) образцов $\left(\mathrm{K}_{0.33}\left(\mathrm{NH}_{4}\right)_{0.67}\right)_{3} \mathrm{H}\left(\mathrm{SO}_{4}\right)_{2}$ имеет более неоднородный рельеф (рис. $3, a, b)$. Сравнение величины среднеквадратической шероховатости $\left(R_{q}\right)$ для наиболее гладких участков поверхности размером $2 \times 2 \mu \mathrm{m}$ показывает ее возрастание: $0.400 \mathrm{~nm}$ $\left(57 \% \mathrm{NH}_{4}\right), 0.445 \mathrm{~nm}\left(67 \% \mathrm{NH}_{4}\right)$ и $0.531 \mathrm{~nm}\left(80 \% \mathrm{NH}_{4}\right)$. На основании статистики измерений шероховатости можно сделать заключение, что при увеличении содержания аммония повышается внешняя удельная поверхность материала и растет его реакционная способность. Если на изображении поверхности (001) кристалла $\left(\mathrm{K}_{0.20}\left(\mathrm{NH}_{4}\right)_{0.80}\right)_{3} \mathrm{H}\left(\mathrm{SO}_{4}\right)_{2}$, полученной свежим сколом при 30\% влажности (рис. 3,c), еще проявляются элементы ступенчатого строения, как и у $\left(\mathrm{K}_{0.33}\left(\mathrm{NH}_{4}\right)_{0.67}\right)_{3} \mathrm{H}\left(\mathrm{SO}_{4}\right)_{2}$ (рис. $\left.3, a\right)$, то при $40 \%$ влажности морфология поверхности видоизменяется (рис. $3, d$ ).

Для характеризации фаз с различным содержанием аммония были измерены локальные ВАХ вдоль 

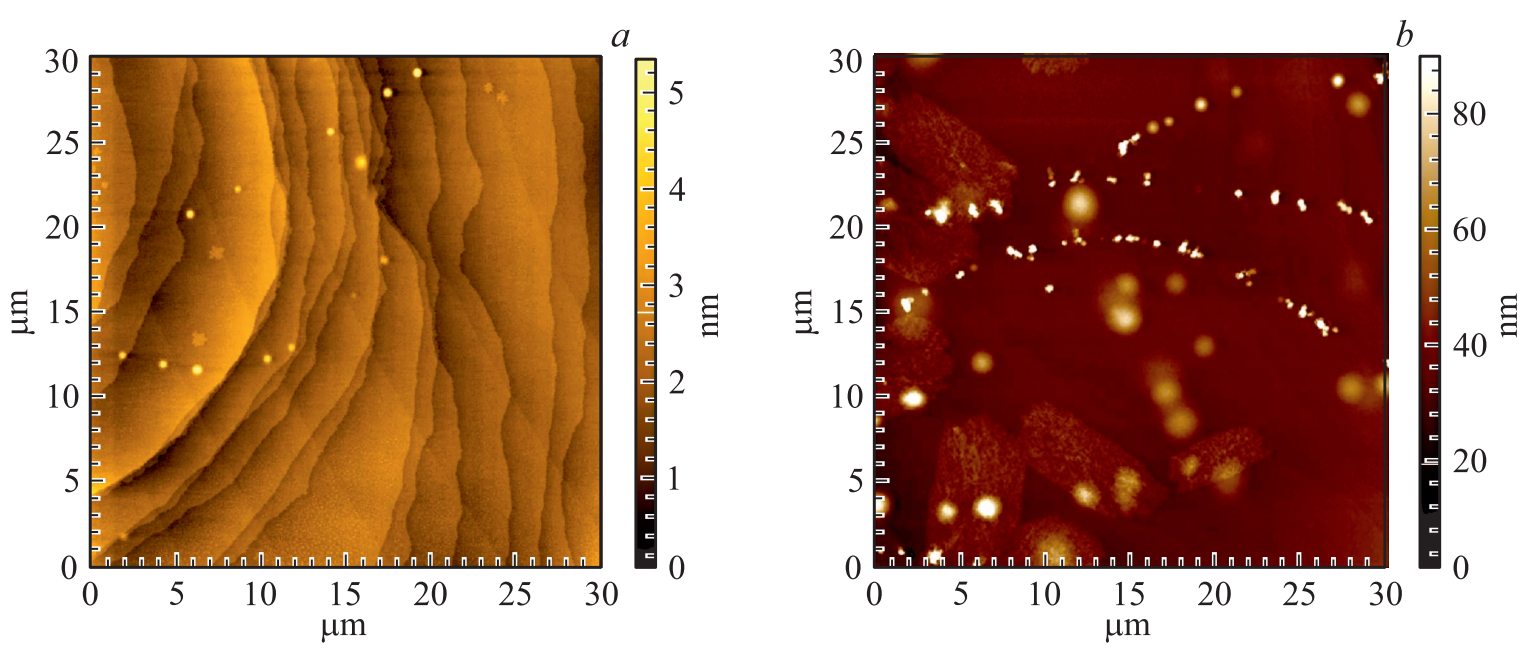

Рис. 5. $a$ - АСМ-изображение ступенчатой поверхности кристалла $\left(\mathrm{K}_{0.43}\left(\mathrm{NH}_{4}\right)_{0.57}\right)_{3} \mathrm{H}\left(\mathrm{SO}_{4}\right)_{2}$ свежего скола и $b-$ ее изменение в течение $24 \mathrm{~h}$ при $30 \%$ влажности воздуха.
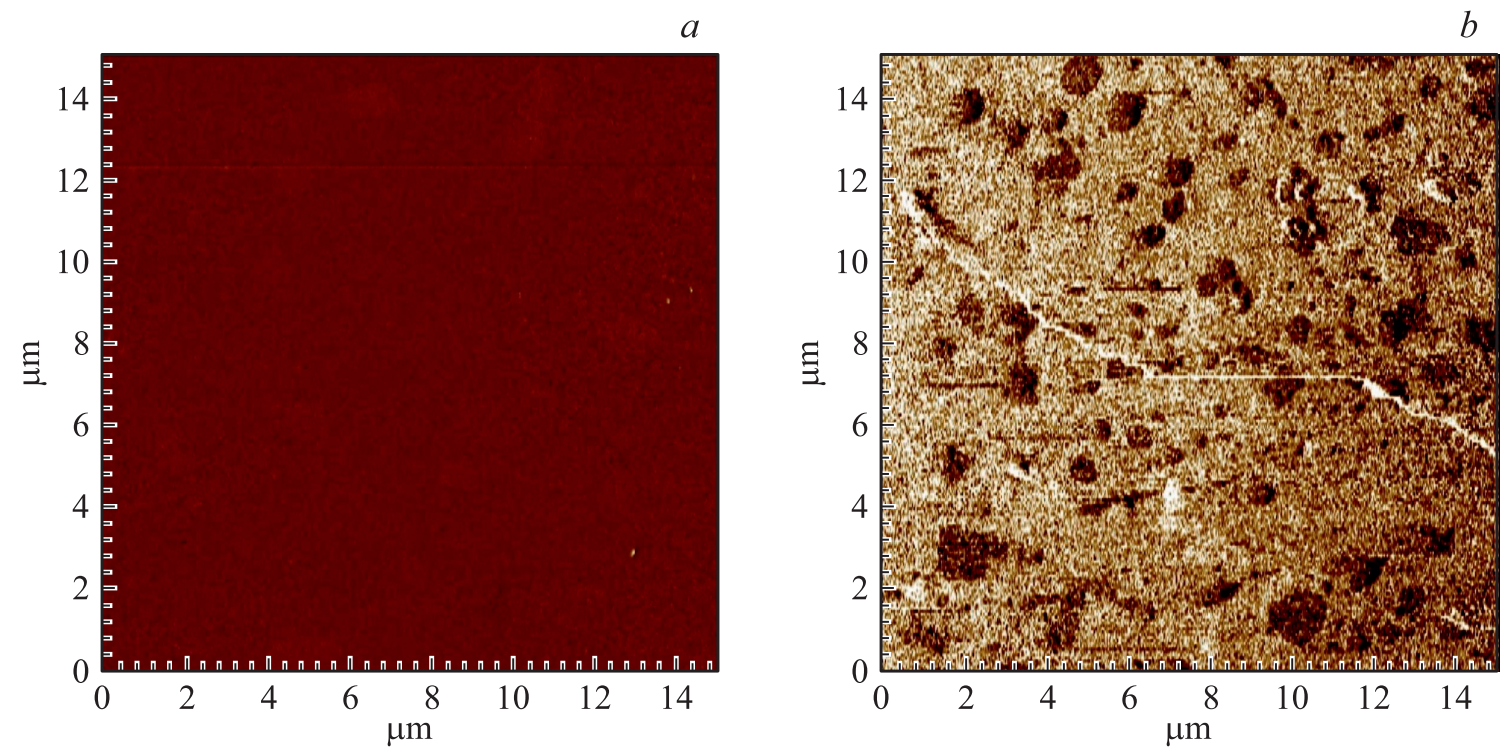

Рис. 6. МПО-изображение полированной поверхности кристалла $\left(\mathrm{K}_{0.43}\left(\mathrm{NH}_{4}\right)_{0.57}\right)_{3} \mathrm{H}\left(\mathrm{SO}_{4}\right)_{2}: a-296, b-282 \mathrm{~K}$. Фаза латерального пьезоотклика.

направления $c$. Результат 20-кратного усреднения данных для каждого состава представлен на рис. 4. Проводимость образца $\left(\mathrm{K}_{0.20}\left(\mathrm{NH}_{4}\right)_{0.80}\right)_{3} \mathrm{H}\left(\mathrm{SO}_{4}\right)$ возрастает (примерно в 6 раз при $U=4 \mathrm{~V}$ ) по сравнению c $\left(\mathrm{K}_{0.43}\left(\mathrm{NH}_{4}\right)_{0.57}\right)_{3} \mathrm{H}\left(\mathrm{SO}_{4}\right)_{2}$ и $\left(\mathrm{K}_{0.33}\left(\mathrm{NH}_{4}\right)_{0.67}\right)_{3} \mathrm{H}\left(\mathrm{SO}_{4}\right)_{2}$. Опираясь на результаты измерений параметров рельефа поверхности свежего скола и проводимости на наноуровне, можно предположить, что замещение катионов (наличие 20\% калия и $80 \%$ аммония) в структуре $\left(\mathrm{K}_{2} \mathrm{NH}_{4}\right)_{3} \mathrm{H}\left(\mathrm{SO}_{4}\right)_{2}$ определенным образом проявит себя и на макроуровне, например во временной кинетике физико-химических процессов, стабильности и деградации суперпротонных фаз.

Опытным путем установлено, что подготовка образцов суперпротонных фаз и условия проведения из- мерений имеют первостепенное значение для получения воспроизводимых результатов, и это относится не только к более реакционно-способной поверхности $\left(\mathrm{K}_{0.20}\left(\mathrm{NH}_{4}\right)_{0.80}\right)_{3} \mathrm{H}\left(\mathrm{SO}_{4}\right)_{2}$. Наглядным примером служит рис. 5, $a$, на котором показана исходная ступенчатая поверхность свежего скола, характерная для кристалла $\left(\mathrm{K}_{0.43}\left(\mathrm{NH}_{4}\right)_{0.57}\right)_{3} \mathrm{H}\left(\mathrm{SO}_{4}\right)_{2}$. Минимальная высота ступеней на участке размером $30 \times 30 \mu \mathrm{m}$ составляет $\sim 0.7 \mathrm{~nm}, R_{q}=2 \mathrm{~nm}$. При хранении образца в течение $24 \mathrm{~h}$ в воздушной атмосфере в условиях чистой зоны и влажности $30 \%$ рельеф кардинально меняется (рис. 5, b): уже не видно даже самих микроступеней. Шероховатость увеличивается по сравнению с исходной примерно в 5 раз $\left(R_{q}=10.4 \mathrm{~nm}\right)$. Изучение токовых изображений, полученных методом ПАСМ, показало, 
что, деградируя, поверхность становится электрически неоднородной: присутствуют проводящие и непроводящие фазы. Это указывает на протекание локальных поверхностных химических реакций в твердой фазе, что должно стать предметом отдельного изучения.

Для изучения суперпротонных фаз с точки зрения наличия фазовых переходов была использована микроскопия пьезоэлектрического отклика, позволяющая визуализировать доменную структуру. Исследование кристаллов $\left(\mathrm{K}_{0.43}\left(\mathrm{NH}_{4}\right)_{0.57}\right)_{3} \mathrm{H}\left(\mathrm{SO}_{4}\right)_{2}$ при комнатной температуре методом МПО не обнаружило пьезоэлектрический отклик как для образцов, полученных свежим сколом, так и после полировки поверхности. На рис. 6, a приведено МПО-изображение участка полированной поверхности (001) кристалла $\left(\mathrm{K}_{0.43}\left(\mathrm{NH}_{4}\right)_{0.57}\right)_{3} \mathrm{H}\left(\mathrm{SO}_{4}\right)_{2}$, которое показывает, что в исходном состоянии при $T=296 \mathrm{~K}$ образец находился в парафазе. При понижении температуры до $282 \mathrm{~K}$ наблюдался переход в сегнетоэлектрическое состояние (рис. 6, $b$ ). На монодоменных участках видны небольшие домены размером около $1 \mu \mathrm{m}$ противоположного знака. Измерение механических свойств в прыжковой моде АСМ обнаружило наличие на исследуемой поверхности небольших участков с твердостью ниже, чем у основной матрицы. При понижении температуры до $278 \mathrm{~K}$ каких-либо изменений структуры не происходило. При нагреве до $296 \mathrm{~K}$ кристалл из сегнетофазы опять переходил в парафазу. Повторное изменение температуры в интервале $278-296 \mathrm{~K}$ показало, что фазовый переход (сегнетофаза-парафаза) обратимый. Полученные микроскопические данные коррелируют с результатами диэлектрической спектроскопии и дополняют данные рентгеноструктурного анализа для кристалла $\left(\mathrm{K}_{0.43}\left(\mathrm{NH}_{4}\right)_{0.57}\right)_{3} \mathrm{H}\left(\mathrm{SO}_{4}\right)_{2} \quad[12,13]$. Однако для уточнения природы сегнетоэлектрического/сегнетоэластического перехода требуются дополнительные исследования, в частности температурные измерения на образцах, полученных свежим сколом, с привлечением комплекса методик прыжковой АCM.

\section{Заключение}

На основе первых экспериментальных исследований морфологии поверхности, фазового перехода и локальных электрических характеристик трех новых изоструктурных кристаллов-суперпротоников $\left(\mathrm{K}_{0.43}\left(\mathrm{NH}_{4}\right)_{0.57}\right)_{3} \mathrm{H}\left(\mathrm{SO}_{4}\right)_{2}, \quad\left(\mathrm{~K}_{0.33}\left(\mathrm{NH}_{4}\right)_{0.67}\right)_{3} \mathrm{H}\left(\mathrm{SO}_{4}\right)_{2} \quad$ и $\left(\mathrm{K}_{0.20}\left(\mathrm{NH}_{4}\right)_{0.80}\right)_{3} \mathrm{H}\left(\mathrm{SO}_{4}\right)_{2}$ с помощью комплекса методов ACM с привлечением данных структурного анализа можно сделать выводы относительно как свойств самих фаз, так и методических тонкостей подобных экспериментов.

Показано, что данные о топографии и локальных электрических характеристиках атомно-гладкой чистой поверхности, формирующейся при расколе кристалла по плоскости спайности, дают дополнительную информа- цию о реальной структуре. На поверхности кристаллов $\left(\mathrm{K}_{0.43}\left(\mathrm{NH}_{4}\right)_{0.57}\right)_{3} \mathrm{H}\left(\mathrm{SO}_{4}\right)_{2}$ обнаружено образование сверхтонких деталей нанорельефа - ямок и выступов с устойчивыми параметрами по высоте (глубине) $\sim 0.7 \mathrm{~nm}$, что соответствует величине $1 / 3 c$ в элементарной ячейке. В этом случае прослеживается корреляция с параметрами слоистой структуры кристалла, найденными методом рентгеноструктурного анализа. При сколе кристалла с повышенным содержанием аммония формируется более неоднородная шероховатая поверхность, которая достаточно быстро деградирует. Скорость, с которой протекают процессы рекристаллизации и трансформируется субповерхностный слой с образованием проводящих и непроводящих фаз, зависит как от процентного замещения калия на аммоний, так и от влажности воздушной среды. Впервые с помощью АСМ получена информация о стабильности и деградации суперпротонных фаз на наноуровне, которая представляет интерес для дальнейших практических применений, например, при создании нанокомпозитов.

С помощью микроскопии пьезоотклика установлено, что при комнатной температуре исследуемые кристаллы находятся в параэлектрической фазе. Впервые методом МПО зарегистрирован сегнетоэлектрический фазовый переход (возможно сегнетоэластический) в кристалле $\left(\mathrm{K}_{0.43}\left(\mathrm{NH}_{4}\right)_{0.57}\right)_{3} \mathrm{H}\left(\mathrm{SO}_{4}\right)_{2}$ при $T \sim 282 \mathrm{~K}$, что находится в согласии с данными диэлектрической спектроскопии и структурного анализа.

Отдельного обсуждения требуют особые свойства поверхности водорастворимых суперпротонных кристаллов, которые следует учитывать при АСМ-исследовании в воздушной атмосфере. Необходимым условием для извлечения информации о структуре и локальных физических характеристиках является подготовка свежих сколов в условиях пониженной влажности воздуха и ее контроля (или в атмосфере азота в условии специальных камер) и быстрое проведение экспериментов с чистой атомно-гладкой поверхностью. Способность поверхности скола деградировать требует одновременных быстрых неразрушающих измерений электрических и механических характеристик, как например в прыжковой $\mathrm{ACM}$, основанной на измерении силовых кривых и обработке сигнала в реальном времени [17].

На пути расширенного использования метода АСМ для изучения связей структура-свойства суперпротонных кристаллов имеются определенные сложности, связанные, с ограниченным числом возможных объектов исследования. Новый суперпротонный кристалл $\left(\mathrm{K}_{0.43}\left(\mathrm{NH}_{4}\right)_{0.57}\right)_{3} \mathrm{H}\left(\mathrm{SO}_{4}\right)_{2}$ оказывается скорее счастливым исключением из общих правил в силу того, что сегнетоэлектрический фазовый переход происходит при пониженных температурах, доступных для современных коммерческих приборов. Следует также отметить ограничения метода АСМ при проведении температурных измерений, связанные с невозможностью точного определения температуры начала фазового перехода в суперпротонную фазу. При измерении локальных ВАХ 
нужна большая статистика, чтобы иметь возможность соотнести полученные данные с объемными. Тем не менее альянс электрических методов АСМ с классическим структурным анализом и диэлектрической спектроскопией открывает новые перспективы в физическом материаловедении суперпротонных кристаллов.

\section{Благодарности}

Авторы выражают благодарность А.С. Калинину (NT-MDT Spectrum Instruments, Зеленоград) за измерения в прыжковой моде АСМ.

\section{Финансирование работы}

Работа выполнена при поддержке Министерства науки и высшего образования РФ в рамках выполнения работ по Государственному заданию ФНИЦ „Кристаллография и фотоника“" РАН и частично при поддержке Программы фундаментальных исследований Президиума РАН 1.2.П № 32. Эксперименты проводились с использованием оборудования ЦКП ФНИЦ „Кристаллография и фотоника“ при поддержке Минобрнауки (проект RFMEFI62119X0035).

\section{Конфликт интересов}

Авторы заявляют, что у них нет конфликта интересов.

\section{Список литературы}

[1] Макарова И.П. // ФТТ. 2015. Т. 57. Вып. 3. С. 432-439. [Makarova I.P. // Phys. Solid State. 2015. Vol. 57. P. 442-449.] https://doi.org/10.1134/S1063783415030117

[2] Баранов А.И., Макарова И.П., Мурадян Л.А., Трегубченко А.В., Шувалов Л.А., Симонов В.И. // Кристаллография. 1987. Т. 32. Вып. 3. С. 682-694. [Baranov A.I., Makarova I.P., Muradyan L.A., Tregubchenko A.V., Shuvalov L.A., Simonov V.I. // Kristallograf. 1987. Vol. 32. N 3. P. 682-694.]

[3] Makarova I.P., Shuvalov L.A., Simonov V.I. // Ferroelectrics. 1988. Vol. 79. P. 111-116. DOI: 10.1080/00150198808229410

[4] Soliman M., Ding Y., Tetard L. // J. Physics: Condens. Matter. 2017. Vol. 29. N 17. P. 173001 (1-24). DOI: $10.1088 / 1361-648 \mathrm{X} / \mathrm{aa} 5 \mathrm{~b} 4 \mathrm{a}$

[5] Oliver R.A. // Rep. Prog. Phys. 2008. Vol. 7. P. 076501 (1-37). DOI: $10.1088 / 0034-4885 / 71 / 7 / 076501$

[6] Electrical Atomic Force Microscopy for Nanoelectronics / Ed. Umberto Celano. NanoScience and Technology Springer. 2019. 408 p. https://doi.org/10.1007/978-3-030-15612-1

[7] Tolstikhina A.L., Gainutdinov R.V., Belugina N.V., Lashkova A.K., Kalinin A.S., Atepalikhin V.V., Polyakov V.V., Bykov V.A. // Physica B: Condens. Matter. 2018. Vol. 550. P. 332-339. https://doi.org/10.1016/j.physb.2018.09.025

[8] Everhardt A.S., Damerio S., Zorn J.A., Zhou S., Domingo N., Catalan G., Salje E.K.H., Chen L.-Q., Noheda B. // Phys. Rev. Lett. 2019. Vol. 123. P. 087603.

https://doi.org/10.1103/PhysRevLett.123.087603
[9] Rodríguez T.R., García R. // Appl. Phys. Lett. 2004. Vol. 84. P. 449-451. https://doi.org/10.10631.

[10] Гайнутдинов Р.В., Толстихина А.Л., Лашкова А.К., Белугина Н.В., Шут В.Н., Мозжсаров С.Е., Кашевич И.Ф. // ЖТФ. 2019. Т. 89. Вып. 11. C. 1692-1698. [Gainutdinov R.V., Tolstikhina A.L., Lashkova A.K., Belugina N.V., Shut V.N., Mozzharov S.E., Kashevich I.F. // Tech. Phys. 2019. Vol. 64. N 11. P. 1602-1608.] DOI: 10.1134/S1063784219110094

[11] Casalini R., Labardi M., Roland C.M. // J. Chem. Phys. 2017. Vol. 146. P. 203315 (1-5). http://dx.doi.org/10.1063/1.4977785

[12] Selezneva E.V., Makarova I.P., Malyshkina I.A., Gavrilova N.D., Grebenev V.V., Novik V.K., Komornikov V.A. // Acta Cryst. B. 2017. Vol. 73. N 6. P. 1105-1113. https://doi.org/10.1107/S2052520617012847

[13] Малышкина И.А., Селезнева Е.В., Макарова И.П., Гаврилова Н.Д. // Вестник Московского ун-та. Серия 3. Физика. Астрономия. 2019. № 4. С. 52-58. [Malyshkina I.A., Selezneva E.V., Makarova I.P., Gavrilova N.D. Moscow University Physics Bulletin. 2019. Vol. 74. P. 392-399.] https://doi.org/10.3103/S002713491904012X

[14] Макарова И.П., Черная Т.С., Филаретов А.А., Васильев А.Л., Верин И.А., Гребенев В.В., Долбинина В.В. // Кристаллография. 2010. Т. 55. Вып. 3. С. 429-439. [Makarova I.P., Chernaya T.S., Filaretov A.A., Vasil'ev A.L., Verin I.A., Grebenev V.V., Dolbinina V.V. // Crystallogr. Rep. 2010. Vol. 55. P. 393-403.] https://doi.org/10.1134/S1063774510030065

[15] Fukami T., Horiuchi K., Nakasone K., Furukawa K. // Jpn. J. Appl. Physics. 1996. Vol. 35(4A). P. 2253-2254.

[16] Belugina N.V., Tolstikhina A.L., Gainutdinov R.V. // Ferroelectrics. 2001. Vol. 249. P. 237-255. DOI: $10.1080 / 00150190108226000$

[17] Интернет Pecypc NT-MDT Spectrum Instruments https://www.ntmdt-si.ru/products/features/hybrid-mode 